\title{
SCHOLARSHIPS OR STUDENT LOANS? SUBSIDIZING Higher EDUCATION IN THE PRESENCE OF MORAL HAZARD
}

\author{
ALESSANDRO CigNO \\ ANNALISA LUPORINI
}

CESIFO WORKING PAPER No. 973

CATEGORY 1: PUBLIC FINANCE

JUNE 2003

Presented at CESifo Area conference on Public Sector Economics, May 2003

An electronic version of the paper may be downloaded

- from the SSRN website: www.SSRN.com

- from the CESifo website: www.CESifo.de 


\title{
SCHOLARSHIPS OR STUDENT LOANS? SUBSIDIZING HIGHER EDUCATION IN THE PRESENCE OF MORAL HAZARD
}

\begin{abstract}
Student loans, even income-contingent ones, are not optimal. Potential university students with the appropriate characteristics should be offered a scholarship, dependent on both need and merit. The award of the scholarship should be conditional on the choice of university degree, but students with a natural aptitude for studies that do not hold the prospect of a well paid job should not be pushed towards potentially more lucrative ones. The scheme should be financed by a graduate tax that re-distributes from the better paid to the academically more successful.
\end{abstract}

JEL Code: D82, I28.

Keywords: scholarships, student loans, graduate tax, principal-agent, moral hazard.

Alessandro Cigno

Dipartimento di Studi sullo Stato

Università di Firenze

Via S. Caterina d'Alessandria 3

50129 Firenze

Italy

cigno@unifi.it
Annalisa Luporini

Dipartimento di Scienze Economiche

Università di Firenze

Via Curtatone 1

50123 Firenze

Italy

luporini@cce.unifi.it 


\section{Introduction}

Whether and in which way the government should help students pay for a higher education is a matter of great practical and theoretical interest. Y et, there is remarkably little analytical work on the subject. ${ }^{1}$ In the presence of full contingent markets allowing potential students to discount expected future incomes, and assuming no external exects of university education, there would be no reason for public concern (distributional considerations could be dealt with separately from education). Since markets are incomplete, however, the young have di $₫$ culty in borrowing against expected future incomes (Stiglitz and Weiss, 1981), and insuring against the risks associated with educational investment. In the absence of policy, a young person's ability to attend university would thus be restricted by the extent to which his parents are able to support him. It is then possible that a number of young people, who could gain from attending university, will not do so. There is thus an argument for relaxing the budget constraint of these young people, and possibly insuring them against the risk of a poor outcome at university or, later, in the market place.

Public intervention may be justi..ed also by an externality argument. If part of the bene.t of a university education accrues to society as a whole, rather than to the person being educated, the cost should not fall entirely on the latter. One such exect arises from the existence of a government budget constraint. Since graduates earn more, on average, than non graduates, an increase in the number of graduates will expand the tax base, and thus bene..t all, including non graduates. Additional externalities arise if a university education increases the productivity, not only of the graduate himself, but also of those who will work with him, or if university graduates raise the cultural level of a country for the bene.t of all. However, such additional external bene.ts may be oxset by the external costs if a university education makes the graduate dissatis.ed with intellectually unchallenging (but nonetheless useful) jobs, or if cultured citizens attract the antipathy of uncultured ones. ${ }^{2}$

The basic policy question is whether the government should use its

\footnotetext{
${ }^{1}$ The importance of education for economic growth is well documented; see, for example, J orgenson and Fraumeni (1992). A good theory-based discussion of different policy proposals regarding the ..nancing of higher education students is in Barr (1991). We are not aware of any formal analysis of whether students should be ..nanced by means of a loan or of a scholarship, and on what conditions.

${ }^{2}$ Especially if the former exercise undue weight over the destination of public expenditure. The usual example given is that of the educated middle classes pushing for public subsidies to art galleries and opera houses, of which they themselves are overwhelmingly the patrons.
} 
superior ..nancial position to help young people with an aptitude for higher education realize their potential. Subsidiary policy questions concern the precise form of the intervention. We hyp othesize an institutional setting where school education is suc ciently subsidized, and the school curriculum suф ciently broad, to allow every young person to reveal both his aptitude for a university education, and his natural predisposition towards the study of one or another subject. For simplicity, we also assume that the net exect of allowing an extra person to go to university on the welfare of those who will not (but not necessarily on the welfare of other graduates) is negligible. This last assumption allows us to restrict the analysis to those young people who would pro..t from a university education in the precise sense that, given full contingent markets, they would have gone to university even without public help. If the number of graduates has a positive exect on the welfare of non graduates, that will only strengthen the argument for a policy that facilitates access to university, and justify ..nancing this policy in part with a levy on the whole population, without necessarily changing the characteristics of the optimal policy in other respects.

A s school records are available to the policy maker, there is no problem of hidden personal characteristics. There is, however, a hidden action problem in that the amount of exort a student puts into his higher education is private information. O ne of the subsidiary questions we shall ask is then how to help students ..nancially, without weakening their incentive to study hard. A nother question arises from the fact that certain university subjects have a higher expected return, in terms of post-graduation income, than others. In what follows, we shall talk of "science" referring to subjects that hold the prospect of a well paid job, of "arts" referring to less pro..table subjects, but that is just short-hand (for present purposes, science includes accountancy, arts includes pure economics). The question is whether students with a natural predisposition for the arts should be allowed to follow their natural inclination, or pushed towards science. Yet another question concerns the allocation of risk. Given that university grades, and the level of income after graduation, depend partly on luck, should the policy include some element of insurance?

A possible solution to the policy problem is a loan guarantee. Loans give students every possible incentive to do well in their studies. However, they distort choice towards subjects with a high earning potential, and discriminate against students from poor families. Both these drawbacks are mitigated if the re-payment is contingent on realized income $^{3}$ An alternative is a scholarship scheme. Scholarships do not dis-

\footnotetext{
${ }^{3}$ The idea of income-contingent loans comes originally from B laug; see B arr (1991).
} 
tort choice, and do not discriminate against students from poor families. However, they give rise to moral hazard, as students (particularly arts students, whose opportunity-cost in terms of expected future income is comparatively small) may choose to have a good time instead of studying hard. Furthermore, a scholarship scheme ..nanced by general taxation is generally thought to be regressive, because graduates earn, on average, more than non graduates. ${ }^{4}$ This shortcoming is avoided if scholarships are ..nanced by a tax on graduates only. The latter should not take us far from the optimum if our assumption of negl igible spill-over exects on non graduates is correct.

Our strategy will beto characterizean optimal transfer scheme whereby students receive money from, and graduates pay money to, an education authority. The characteristics of these payments at the optimum will reveal whether the optimal policy is a loan or a scholarship scheme. The policy optimization has the logical structure of an agency problem, with the education authority in the role of principal, and potential students in that of agents. We shall assume that the objective function of the principal is the sum of the objective functions of the agents, so that the interests of the former are not diametrically opposed to those of the latter. $^{5}$

\section{A gents}

In the present context, an agent is someone who just ..nished school with suф ciently high grades to make him university material. University material means that, were this person able to trade in full contingent markets, he would be better-o going to university than straight into the labour market. Suppose there are only two types of agent, a (for "arty") and (for "scienti..c"). We assume that the education authority has access to school records, and thus knows which potential students are of type $a$, and which are of type $s$. The analysis covers two periods: period 1, when an agent can be either a student or a young worker, and period 2, when he is either a graduate or a non-graduate worker.

Let $\mathrm{e}$ (belonging to the closed interval $E=[e, \bar{e}] 2 R^{+}$) denote study exort by student $\mathrm{j}$, and e the vector of exorts put in by the dixerent

\footnotetext{
${ }^{4} \mathrm{~T}$ his point was made by Friedman (1962) and is supported by empirical research in Hansen and Weisbrod (1969). Since then, several empirical studies have addressed the question of the distributional impact of subsidies to higher education. Some papers support the "F riedman thesis", but most of them sem to ..nd that the impact is progressive. Nevertheless, conventional wisdom sems to favour the view that subsidies are regressive; see, e. g., the discussion in B arbaro (2002).

${ }^{5} \mathrm{~A}$ policy problem with a similar structure is in Cigno, Luporini and Pettini (2002). There, however, the role of agent is plaid by parents of young children, not by the children themselves, and the issues are quite dixerent.
} 
students. ${ }^{6}$ Similarly, let $d$ denote thetype of degree chosen by student $j$, and $d$ the vector of degree types chosen by all students. We characterize a degree by the proportion of science subjects included in it $(d=0$ if the curriculum consists entirely of arts subjects, $d=1$ if it includes only science subjects). Exort is not observable, but the choice of degree is.

The ..nal degree result of student $j$ is denoted by $x^{j}$ (belonging to the closed interval $X=[X ; \bar{X}] 2 R),{ }^{7}$ and those of all students by the vector $x$ : Ex ante, degree results are distributed with joint density $f(x ; e)$, assumed known. ${ }^{8}$ Having assumed that the characteristics (a or $\mathrm{s}$ ) of each agent are also known, the uncertainty surrounding the realization of $x^{j}$, for any given $e^{j}$, is purely the exect of luck in university examinations. Studying harder does, however, make it more likely that a student will obtain high grades, in the precise sense that the cumulative distribution of $x^{j}$ associated with a higher $e^{j}$ stochastically dominates that associated with a lower $\mathrm{e}$.

In period 1, agents decide whether to attend university or go straight into the labour market. If agent $\mathrm{j}$ chooses to be a student, he receives $m_{1}^{j}+y^{j}$. We may interpret $m_{1}^{j}$ as parental support, and $y^{j}$ as either a loan (guaranteed by the government) or a scholarship. The vector of parental support levels, and that of the scholarships or loans, received by the dixerent students are respectively represented by $m_{1}$ and $y$. If the agent chooses to go straight into the labour market, he earns $w_{1}$ (all young workers earn the same). Both $m_{1}$ and $w_{1}$ are de. ned net of any general income tax. Both are certain, and known. In assuming this of $m_{1}$, we are in exect saying that, if a young person goes to university, his parents are somehow obliged to support him at some level (dependent on their means)..$^{9}$ Were that not the case, parents would in fact be tempted

\footnotetext{
${ }^{6}$ If there were only two students, one of each type, we could simply write $e^{a}$ and $\mathrm{e}^{\mathrm{s}}$. Since there are many agents of the same type, however, we keep to the generic $\mathrm{j}$ index.

${ }^{7}$ In some university systems, there is an actual degree result. In others, we may think of the degree result as of the average of the grades obtained in individual exams.

${ }^{8} \mathrm{We}$ assume that the monotone likelihood ratio (MLR) condition, namely that $\left(\frac{f_{e j}}{f}\right)$ is increasing in $x^{j}$, holds with respect to agent $j^{\prime} s$ exort, and that the upper cumulative probabilities of $x^{j}$ are nondecreasing and concave in $e^{j}$. These assumptions guarantee that the ..rst order approach is valid in multi-signal principal-agent models (Sinclair-Desgagné, 1994). By ensuring uniqueness of the agent's choice of exort, they will al low us to substitute the ..rst-order condition of the agent's problem for the incentive compatibility const raint in the principal's optimization problem (see section 3).

${ }^{9} \mathrm{~T}$ hat used to be the case, for example, in pre-Thacher UK, where the grant awarded to a student admitted to university included a mandatory parental support element, calculated on the basis of parental income.
} 
to free-ride.

In period 2 , agent $j$ gets $w_{2}+m_{2} i i^{j}$ if he is a graduate, $w_{2}$ if he is not. We interpret $w_{2}$ as the earnings of a non-graduate adult worker (the same for everyone), and $\mathrm{m}$ as a skill premium. Depending on whether $y^{j}$ is a loan or a scholarship, $i^{j}$ is either a loan re-payment or a graduate tax. All payments are discounted back to period 1 at the given rate of interest. ${ }^{10}$ The vector of the skill premia earned by the dixerent agents is denoted by $m_{2}$, that of the loan repayments or graduate taxes by $i$. Both $w_{2}$ and $m_{2}$ are net of any general income tax (raised by the government for purposes other than university education, and payable by everyone).

We assume that both $m_{2}$ and $w_{2}$ are observable ex post. While $w_{2}$ is certain and known in advance, however, $m_{2}$ is distributed ex ante with known joint density $g\left(\mathrm{~m}_{2} ; \mathrm{x} ; \mathrm{d}\right)$, conditional on degree types and degree results. The cumulative distribution of $\mathrm{m}_{2}^{j}$ associated with a higher $\mathrm{d}$ or $x^{j}$ stochastically dominates that associated with a lower $\mathrm{d}^{j}$ or $\mathrm{x}^{\mathrm{j}}$. In other words, higher grades, or a degree with a higher science content, make it more likely that the graduate will get a high income in period 2. For any given $d$ and $x^{j}$, the uncertainty surrounding the realization of $m_{2}^{2}$ refects $j$ 's luck in ..nding a well paid job.

Let $z^{j}\left(d ; e^{d}\right)$ be the cost of studying the subject mix $d^{j}$ for student $\mathrm{j}$. This cost includes not only the actual expenses incurred, and the current income forgone, in attending university, but also the consumption equivalent of the disutility of study exort. ${ }^{11}$ This disutility may well be negative for certain values of $d$ and $e^{j}$ (in other words, at least up to a certain exort level, studying the subjects of one's choice may be a pleasure). Even though the other cost components are necessarily positive, $z^{j}$ may thus have any sign. To ensure convexity, we assume that the marginal cost of exort is positive and increasing for all students $\left(z_{\mathrm{e}}>0, z_{\mathrm{e} e}>0\right)$. We also assume that, as the subject mix becomes more scienti..c, the cost of getting a degree increases for the a type, but not necessarily for the sone; in any case, it increases more for the former than for the latter (if $j$ is an $a$, and $k$ is an $s, z_{d j}^{j}>z_{d^{k}}^{k}$ ). Similarly, we assume that an increase in the science content of the degree raises the marginal cost of exort if the student has a natural disposition towards the arts, but not necessarily if he is predisposed towards the study of science; in any case, it raises it more for the former than for the latter (if $j$ is an $a$, and $k$ is an $s, z_{e^{j} d j}^{j}>z_{e^{k} d^{k}}^{k}$ ). The function $z^{j}(:)$ is known

\footnotetext{
${ }^{10}$ Recall that, although agents cannot borrow, the principal can. Expressing period-2 payments in period-1 money avoids carrying the discount factor around.

${ }^{11}$ We may similarly think of $w_{t}$ as earnings net of the consumption-equivalent of the disutility of labour.
} 
to all concerned.

Ex post, the lifetime utility of agent $\mathrm{j}$ is given by

$$
U^{j}=u_{1}^{3} c_{1}^{j}+u_{2}{ }^{3} c_{2}^{j^{\prime}} ;
$$

where $c_{1}$ is the consumption of agent $j$ in period $t$. The functions $u_{t}(:)$ are assumed increasing and concave, with $u_{t}^{0}(0)=1$. In the absence of credit markets allowing young people to borrow against expected future income, agent $\mathrm{j}$ faces a separate budget constraint for each period. In the absence of insurance markets allowing him to insure against poor university results, his consumption in period 1 is then given by

$$
c_{1}^{j}=m_{1}^{j}+y^{j} i z^{j}
$$

if he goes to university, by

$$
c_{1}^{j}=w_{1}
$$

if he does not. In the absence of insurance markets allowing him to insure against bad luck in the graduate labour market, his consumption in period 2 is

$$
c_{2}^{j}=w_{2}+m_{2}^{j} i i^{j}
$$

if $\mathrm{j}$ is a graduate,

$$
c_{2}^{j}=w_{2}
$$

if he is not. B oth $y^{j}$ and $i^{j}$ may be functions of any of the observed variables. Thus, $y^{j}$ may depend on $m_{1}$, and be conditional on the realization of $x$, while $i^{j}$ may depend on any of $m_{1}, m_{2}, x$ and $y$.

For the generic agent ( $\mathrm{j}$ index omitted), the pay-ox to being a student, denoted by $1 / \overline{4}\left(m_{1} ; w_{2} ; y ; i\right)$; is the value of his expected utility,

$$
E(U)={ }_{x}^{Z} u_{1}\left(c_{1}\right) f d x+{ }_{x m_{2}}^{Z} u_{2}\left(c_{2}\right) g d m_{2} f d x ;
$$

with $C_{1}$ and $C_{2}$ given by (2) and (4), maximized with respect to the agent's choice of e and $d$. The latter satis..es the ..rst-order conditions

$$
{ }_{i}^{z} u_{1}^{0} z_{e} f d x+{ }_{x}^{z} u_{1} f_{e} d x+{ }_{x m_{2}}^{z ~} u_{2} f_{e} g d x d m_{2}=0
$$

and

$$
i_{x}^{z} u_{1}^{0} z_{d} f d x+{ }_{x m_{2}}^{z ~ z} u_{2} f g_{d} d x d m_{2}=0:
$$

The pay-o to being a young worker, denoted by $1 / 4\left(w_{1} ; w_{2} ; i\right)$, is the value of the agent's expected utility, with $c_{1}$ and $c_{2}$ determined by (3) and (5): 
The agent will choose to be a student if and only if

$$
1 / 4\left(m_{1} ; w_{2} ; y_{i} i\right), 1 / 4\left(w_{1} ; w_{2}\right):
$$

In other words, a person will not go to university if so doing would leave him worse-ox than going straight into the labour market. Therefore, in the absence of public support, or if this were not su $\$$ ciently generous, a number of agents would not attend university. That would have a social cost because, by de. nition of agent, the expected gain from a university education is greater than the cost.

\section{Principal}

The principal is an education authority with the power to guarantee student loans, or to pay out scholarships ..nanced by a debt issue, and recover the cost by raising education-speci...c taxes (a "graduate tax"). The authority chooses $(e ; d ; y ; i)$ so as to maximize the sum of the expected utilities of the agents,

$$
{ }_{j}{ }_{x}^{\mu Z} u_{1}{ }^{3} d_{1}^{\prime}+{ }_{m_{2}} u_{2}{ }^{3} c_{2}^{j} g d m_{2}{ }^{9} f d x \text { " ; }
$$

subject to (2) i (5) for each $j$, and to a number of other restrictions.

Since the authority is ultimately responsible for the cost of $y$, irrespective of whether the elements of $y$ are scholarships or guaranteed loans, a restriction on the education authority's choice of policy is the intertemporal budget constraint,

$$
x_{j}^{\mu Z \mu{ }_{x}^{j} i^{Z}{ }_{m_{2}} i^{j} g d m_{2}^{j}} \stackrel{q}{f} d x^{q} \cdot 0 \text {; }
$$

where $y^{j}$ and $i^{j}$ may be contingent on any of the observed variables. Writing this constraint in expected value terms implies that the principal faces no uncertainty about how much it will have to pay out in total to students in period 1, and how much it will get back in total from graduates in period 2. Therefore, the number of agents is "large". This could mean either that there are many students of each type, or that there are many types of student. Having assumed that there are only two types ( $a$ and $s$ ), there must then be many students of each type.

In addition to the intertemporal budget constraint, the principal faces two restrictions for each agent $\mathrm{j}$ : One is that the principal's choice of $\mathrm{e}$ must satisfy an incentive-compatibility constraint in the form of (7). There is no such restriction on the principal's choice of $d$, because the 
subject mix is observable, and thus controllable. ${ }^{12}$ The other is a participation constraint in the form of (9). If individual exort were observable by the education authority, neither of these additional restrictions would be binding for any of the agents. If individual exort is not observable, it can be shown, using standard techniques, that the incentivecompatibility constraints are binding. Since the same is not necessarily true of the participation constraints, however, we shall develop the argument assuming, at ..rst, that none of the these constraints is binding. Then, we shall see what happens if the assumption is relaxed.

The ..rst-order condition on the principal's choice of $y^{j}$ is

$$
\left(u_{1}^{0} i,\right) f+{ }^{1 j}{ }^{3} i u_{1}^{\prime \prime} z_{e}^{j} f+u_{1}^{0} f_{e}{ }^{\prime}=0 ;
$$

where, is the Lagrange multiplier associated with the principal's budget constraint, and ${ }^{1 \mathrm{j}}$ the Lagrange multiplier associated with the incentive compatibility constraint concerning j's exort.

In ..rst best $\left({ }^{j} \mathrm{j}=0\right.$ for all $\left.\mathrm{j}\right)$, (12) reduces to $u_{1}^{0}=$, implying that each agent must be guaranteed a certain $\dot{C}_{1}$, irrespective of $m_{1}^{j}$ and $x^{j}$. The ..rst-best policy thus redistributes from rich to poor students, and across states of nature. In other words, if exort were observable, it would be optimal for the authority to fully compensate students for any dixerence in the cost of getting a degree, or shortfall in the amount of support received from their parents. It would also be optimal to provide each student with full insurance against the risk of getting a poor degree result (or failing outright) in period 1. This "full insurance" result is standard in principal-agent models. In standard principal-agent models, however, it descends from the assumption that the principal is less riskaverse than the agent. Here, by contrast, the principal is as risk-averse as any of the agents, and the result descends from the fact that the principal does not face any ..nancial risk. ${ }^{13}$

If individual exort is not observable, the principal must be content with second best. $A s^{1 \mathrm{j}}$ is then positive, (12) may be rewritten as

$$
\frac{\partial}{u_{1}^{0}}=1+{ }^{j j} r z_{e}^{j}+\frac{f_{e}(x ; e)}{f(x ; e)} \text {; }
$$

where

$$
r^{\prime} i \frac{u^{\prime \prime}}{u^{0}}
$$

\footnotetext{
${ }^{12}$ It can be controlled by oxering the agent a kind of contract ("forcing contract"): "if you choose the di I tell you, I shall pay you the optimal y now, and charge you the optimal $i^{j}$ next period; if you do not, I shall pay you a lower (even zero) $y^{j}$ now, or charge you a punitive $i^{j}$ next period."

${ }^{13}$ T he same occurs in C igno, Luporini and Pettini (2002), which also has a principal maximizing the sum of the expected utilities of a large number of agents.
} 
is the Arrow-P ratt measure of absolute risk aversi on (assumed constant). Since the r.h.s. of (13) is increasing in $x^{j}$, and the l.h.s. increasing in $C_{1}$, the amount paid to the student, $y^{j}$, must be an increasing function of the student's degree result, $x^{j}$. It must also be higher for students with lower parental support, $m_{1}^{j}$, or higher cost of attending university, $z^{j}$. As in ..rst best, the policy will thus re-distribute in favour of students from poorer families, and of students who (because of their personal characteristics, or choice of subject mix) face a higher cost of education. Perfect equality will not be achieved, however, because students must now be given an incentive to study hard. The more costly it is to provide a certain type of student with this incentive, the more his choice of exort level will be distorted.

If the random variable axecting the degree result of student $j$ (for any given level of exort) is stochastically independent of those axecting the degree results of other students, the second-best value of $\mathrm{y}^{\mathrm{j}}$ does not depend on the results obtained by other students. Otherwise, the likelihood ratio $\frac{f_{\mathrm{j}}(x ; e)}{f(x ; e)}$ will be a function of the entire $x$ vector $(\mathrm{Holm}-$ ström, 1982; M ookherjee, 1984). If that is the case, and if the random variables axecting degree results for any given level of exort are aф liated and dependent, ${ }^{14}$ the second-best $\mathrm{y}^{\mathrm{j}}$ is increasing in $\mathrm{x}^{\mathrm{j}}$, and decreasing in $x^{k}(j \in k)^{15}$. In other words, ranking matters. An implication is that grade drift should not fool the education authority into granting larger loans or higher scholarships to everybody.

The ..rst-order conditions on the principal's choice of $d$ and $e$ are long and unwieldy. We approach them one step at a time. Using (13), the conditions for a ..rst best may be written as

$$
\begin{aligned}
& \text { Z Z } 3 \\
& x m_{2} u_{2}+, i^{j} f g_{d i} d x d m_{2}=, z_{d j}^{j}
\end{aligned}
$$

and

$$
\begin{aligned}
& z z^{3} u_{2}+, i^{j} f_{e j} g d x d m_{2}=, z_{e j}^{j} ;
\end{aligned}
$$

\footnotetext{
${ }^{14} \mathrm{~A} \&$ liation implies that the random variables tend to "move together". In other words, if variables are a $\$$ liated, it is more likely that their realized values will be all high, or all low, than that some will be high, and others low. A $\$$ liation includes the case of ind ependence. Since ac liated random variables have nonnegative covariance, aф liation can be seen as a form of positive correlation (provided that such covariance exists). Here, we consider the case of dependent at liated random variables. For a formal discussion, see the Appendix.

${ }^{15} T$ hat $y^{j}$ increases in $x^{j}$ when $\frac{f_{e j}(x ; e)}{f(x ; e)}$ is monotone in $x^{j}$ is a well known result (see, e.g., M as-C olell, Whinston and $G$ reen, 1995). That $y^{j}$ monotonically decreases in $x^{j}$ when the random variables are aф liated is proved in L uporini (2002). A sketch of the proof is given in the A ppendix.
} 
where the I.h.s. is the expected exect of either $d$ or ed on the principal's optimization (the more science subjects agent $j$ takes, or the harder he studies during period 1, the more he is expected to earn, and pay in taxes, during period 2). What does that tell us about the choice of exort and subject mix for agent $\mathrm{j}$ ?

Let us specialize the analysis a little by assuming that the cost of a university education increases with its science content for students with a natural disposition towards the arts, but decreases for those who are predisposed to the study of science $\left(z_{d j}^{j}\right.$ positive or negative, depending on whether $\mathrm{j}$ is an a or an $\mathrm{s}$ ). Since a degree with a high science content pays, on average, more than a degree with a high arts content, an $\mathrm{S}$ will then study science subjects only $(d=1)$. By contrast, an a will not necessarily study arts subjects only $(d, 0)$, because a lower $d$ is associated with a lower expected $\mathrm{m}_{2}$. Therefore, (15) holds for an a, but not for an s. The argument runs as follows.

If e were the same for both types, the r.h.s. of (16) would be higher for the $a$, than for the s type. We shall see below that $i^{j}$ is generally higher for the latter. This, together with the fact that s-types earn more than a-types, implies that the l.h.s. would then be higher for the former, than for the latter. Therefore, in ..rst best, e will be higher for the scienti...c than for the arty type. The same would be true if $z_{d j}^{j}$ were positive for students predisposed to the study of science (in which case, these students would not necessarily study science subjects only), but still increasing more slowly for this than for the other type of student as assumed.

We have thus found that, in ..rst best, the arty type will not only take less science subjects, but also supply less exort, than the scienti...c type. Intuitively, that is because the expected return to investing in a university education is lower for the former than for the latter. Since the principal is maximizing the sum of the expected utilities (not the sum of the incomes, or abilities to pay tax) of the agents, it then follows that students with scienti..c talent should optimally invest more in their education (put in more exort, sacri..ce more current consumption), than students with a natural disposition towards the arts.

In second best, the ..rst-order condition on d may be written as

$$
B^{j} i C^{j}+E^{j}=1^{3}{ }^{3} D^{j} i F^{j} ;
$$

where

denotes the expected cost,

$$
c^{j},{ }_{x}^{z} u_{1}^{0} z_{d} f d x
$$

z z

$B^{j}{ }_{x m_{2}} u_{2} f g_{d j} d x d m_{2}$ 
the expected private bene.t, and

$$
E^{j},{ }_{x m_{2}}^{Z} i^{j} f g d d x d m_{2}
$$

the expected external bene..t (through thegovernment budget constraint) of inducing agent $\mathrm{j}$ to take more science subjects. The term

$$
D^{j},{ }_{x}^{z_{3}} i u_{1}^{\prime \prime} z_{e j}^{j} z_{d j}^{j} f+u_{1}^{0} z_{e j d j}^{j} f+u_{1}^{0} z_{d i} f_{e j} \quad d x ;
$$

is the exect of a higher $d$ on the expected marginal disutility of exort. It is thus the expected indirect exect on $j$ 's period-1 utility of inducing this agent to take more science subjects. If both $z_{d}^{j}$ and $z_{e d j}^{j}$ are positive, $D^{j}$ is clearly greater than zero. If $z_{d i}^{j}$ and $z_{d d j}^{j}$ are positive for the $a$ type, but negative for the $s$ type, $D^{j}$ is positive (and $d=1$ as in ..rst best) for the former, but negative for the latter. The term

$$
F^{j},{ }_{x}^{Z} m_{2} u_{2} f_{e j} g_{d i} d x d m_{2} ;
$$

also positive, is the expected indirect exect on agent $\mathrm{j}$ 's period-2 utility of pushing agent $\mathrm{j}$ towards science.

If time preference is su $\phi$ ciently high, $D^{j}$ i $F^{j}$ is positive for a-type agents. $A s B^{j}+E^{j}$ must then be larger than $C^{j}$, this means that $d^{j}$ will be lower than in ..rst best for this type of agent. Therefore, the second-best scheme actually encourages students with an aptitude for the arts to specialize further in their preferred subjects than they would in ..rst best. The intuitive explanation is that, as exort is not observable, and providing the agent with the right incentive is consequently costly, the principal makes it easier for the arty student to get higher grades by reducing the science requirement. If $z_{d}^{j}$ and $z_{e d d}^{j}$ are negative for s-type students, agents of this type will be at a corner $(d=1)$; if they are positive, $d$ is lower than in ..rst best for $s$ types too. Otherwise, we cannot say whether $d$ is higher or lower than in ..rst best.

The condition on $\mathrm{e}$ is of diф cult interpretation. Let

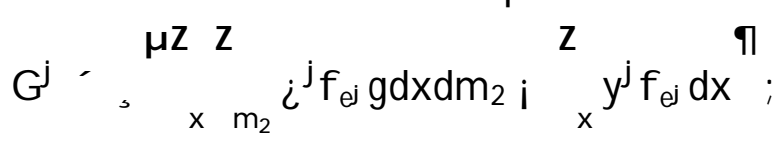

denote the net exect, which may be shown to be positive, of $e$ on the principal's pudget constraint. $G^{j}$ is the sum of two partial exects. The .rst one, $\times m_{2} i^{j} f_{e j} g d x d m_{2}$, arises from the fact that, the harder agent j studies during period 1, the more he is likely to earn and thus, if $i^{j}$ is increasing in $m_{2}^{j}$, pay in taxes or loan repayment during period 2. The second partial exect, $i{ }_{x} y^{j} f_{e} d x$, tells us that, the harder $j$ 
studies during period 1, the larger the scholarship or the loan that he gets during period 1 . If we assume that the random components of the dixerent el ements of $x$ are uncorrelated, the condition on $e$ is that $G^{j}$ must be equal to an unwieddy expression (not reported), positive for the agent's second-order conditions, representing the net exect of $\mathrm{e}$ on the incentive compatibility constraint for agent $\mathrm{j}$. Under this assumption, we can say that the second-best choice of $\mathrm{e}$ islower than in ..rst best, but we cannot say whether it is still lower for the arty than for the scienti..c type (because it may cost the principal less to give the incentive to a, than to $s$ types). ${ }^{16}$ If the random components are correlated, the condition contains additional terms (representing cross-exects), that make it quite impossible to say anything about the second-best choice of $\mathrm{e}$.

The .r.st-order condition on the amount (loan repayment or graduate tax) that agent $\mathrm{j}$ must pay in period $2, \mathrm{i}^{\mathrm{j}}$, is

$$
i u_{2}^{0} f+, f_{i}{ }^{1 j} u_{2}^{0} f_{e}=0 ;
$$

which may also be written as

$$
\frac{3}{u_{2}^{0} w_{2}+m_{2}^{j} i i^{j}}=1+{ }^{j} \frac{f_{e}(x ; e)}{f(x ; e)} \text { : }
$$

In ...rst best $(1 \mathrm{j}=0)$,

$$
u_{2}^{0^{3}} \mathrm{~m}_{2}^{\mathrm{j}} \mathrm{i} \dot{i}^{j}=\text {, }
$$

What (20) says is that all graduates must be assured the same level of consumption in period 2, irrespective of the state of nature, and irrespective, also, of what happened in period 1 . Therefore, the ..rst-best $i^{j}$ is an increasing function of $m_{2}^{j}$. Since, on average, science graduates have higher income than arts graduates, the ..rst-best policy then re-distributes income from science to arts graduates.

In second best $(1 \mathrm{j}>0)$, the principal must take into account also the disincentive exect of $i^{j}$ on study exort. Hence, $i^{j}$ is decreasing in $x^{j}$. This may modify the ..rst-best conclusion that science graduates must pay more than arts graduates. In ...rst best, $\mathrm{e}$ is in fact lower for a than for s types. This is not necessarily true in second best. If, however, the exort level is lower for the arty type, and the marginal distributions of $x^{j}$ are the same (in other words, greater exort has the same exect on the probability of getting high grades) for both types, it then follows

\footnotetext{
${ }^{16}$ The tradeox between productivity and incentive costs is analyzed in Kim (1995) and Robbins and Sarath (1996).
} 
that the expected $\mathrm{x}$ will be lower for the arty type. ${ }^{17}$ Hence, period-2 consumption must be lower for the latter.

Since the second-best $i^{j}$ is increasing in $\mathrm{m}_{2}^{\mathrm{j}}$, and the second-best $\mathrm{m}_{2}^{\mathrm{j}}$ is likely to be lower for a than for $s$ types (because, for the same degree result, arts graduates have lower income on average, but also because arts students are induced to put in less exort, and will thus get lower degree results on average), it is unlikely that $i^{j}$ will be larger for the former than for the latter, but the opposite cannot be excluded a priori. In other words, arts graduate pay on average less than science graduates, but there is no reason why a highly successful arts graduates should be asked to pay less than an equally successful science graduate.

If the random components of the $x$ vector are dependent and ac liated, the second-best $i^{j}$ is decreasing in $x^{j}$, but increasing in the other elements of $x$. Therefore, not only $y^{j}$, but also $i^{j}$, should take account of $j$ 's ranking in terms of degree result. By contrast, even if the random components of the vector $m_{2}$ were not independent, the second-best $i^{j}$ would still depend on $m_{2}^{j}$ only, because the marginal utility of $j$ 's consumption does not depend on that of other people. A positive (negative) macroeconomic shock, bringing all graduate incomes up (down), should thus bring all the elements of $i$ up (down).

Let us now consider the possibility that the participation constraint is binding for some agents. As already pointed out, that will never happen in ..rst best. It may be true in second best, however, because the cost to the principal of providing some agent with the incentive to study hard could outweigh the expected bene.t of sending him to university. If the constraint is binding for anybody, that is likely to be the arty type, because these students have a lower expected period-2 income, for any given private cost, than the scienti..c type. That does not necessarily mean that arts graduates will have lower period-2 consumption than science graduates, however, because the authority will re-distribute in their favour. In second best, however, equality is not achieved (and, the higher the cost to the principal of providing arty students with the incentive to study hard, the further we shall be from equality). It could thus happen that the period- 2 gain is not large enough to compensate the pot ential arts student for the period-1 loss from attending university. If that is the case, not all agents will (apply for a loan or scholarship to hel $p$ them) go to university.

Let $\grave{A}$ be the Lagrange multiplier associated with the participation constraint (9) for agent $j$. If the constraint is binding for agent $j$, the

\footnotetext{
${ }^{17} \mathrm{~N}$ ote that, due to our assumptions, $\mathrm{x}^{\mathrm{j}}$ could be lower for the arty than for the scienti..c type even if $\mathrm{e}^{\mathrm{j}}$ were higher for the former than for the latter.
} 
I.h.S. of (13) becomes $\frac{, i\left(\grave{A}^{j}=p^{j}\right)}{u_{1}^{0}\left(m_{1}^{j}+y_{j}^{j} x^{j}\right)}$. A s $A^{\prime}$ is positive, the second-best $y^{j}$ is then larger than it would be otherwise. A similar argument applies to $i^{j}$. If the participation constraint is binding, the I.h.S. of (19) becomes $\frac{i\left(\dot{A}^{j}=p^{j}\right)}{u_{2}^{0}\left(w_{2}+m_{2}^{j} i i^{j}\right)}$. The second-best $i^{j}$ is then smaller than it would be otherwise. If, as seems likely, the agent in question is of type a, the policy re-distributes even further in favour of these students. That is as one would have expected, because arts students gain less than science students from a university education.

We now come to the central question, whether the optimal (..rst or second best) policy is a loan or a scholarship scheme. Having found that, whether exort is observable or not, the period-2 payment required of agent $j, i^{j}$, should be independent of the amount paid to him in period $1, y^{j}$, we can conclude that $y^{j}$ is not a loan, and that $i^{j}$ cannot be construed to be a loan repayment. In the ..rst-best solution, $\mathrm{y}^{\mathrm{j}}$ is exectively a personalized lump-sum subsidy, and $i^{j}$ a personalized lump-sum tax. If exort were observable, the education authority would in fact know all there is to be known about potential students. ${ }^{18}$ in the second-best solution (exort not observable), yj may be interpreted as a scholarship conditional on both need and merit, and $i^{j}$ as a tax conditional on income and merit. There is nothing to suggest that the optimal $\mathrm{y}^{j}$ is additively separable into two payments, one dependent on "need" $\left(m_{1}^{j}\right)$ only, and the other dependent on "merit" $\left(x^{j}\right)$ only.

Both the ..rst and the second-best policy re-distribute from the relatively rich to the relatively poor (from students with high parental support to students with low parental support, from science graduates, who earn on average more, to arts graduates, who earn on average less). The second-best scheme re-distributes al so from the less to the more academically successful. The second-best scholarship is in fact decreasing in parental support, and increasing in university results. The second-best graduate tax is increasing in graduate income, and decreasing in academic performance. Both the award of the scholarship, and the amount of the tax, are conditional on the agent taking a prescribed course of study (but this does not go against, if anything encourages, the student's predisposition). If the agent chooses otherwise, he will either not get the scholarship, or be charged a punitive tax.

\footnotetext{
${ }^{18}$ Parental support, and aptitude for dixerent types of study, are assumed known anyway.
} 


\section{Discussion}

Our analysis started from the premise that, in the absence of full contingent markets, a number of young people who would have otherwise attended university education will not do so. It may thus be possible to increase social welfare by hel ping these young persons to attend university. The question is how. Loans give students every incentive to apply themselves, but distort choice towards subjects with a higher earning potential; they are also unfair to students from poor families. Scholarships do not distort choice, but give rise to a moral hazard problem in that students of subjects with limited earning potential may be tempted to shirk. If they are ..nanced out of general taxation, scholarships may also be unfair to non graduates.

Our answer is that potential university students with the right characteristics (such that they would choose to attend university in the presence of full contingent markets) should be oxered a scholarship dependent on both "need" (parental support) and "merit" (academic performance). The scheme should be ..nanced by a graduate tax designed so as to re-distribute income from the better paid, to the academically more successful (as well as from students coming from richer family to students coming from poor ones).

The award of a scholarship should be conditional on the choice of university degree (those who choose to do otherwise should be denied a scholarship, or charged a punitive tax). But students with a natural aptitude for studies that do not hold the prospect of a well paid job ("arts") should not be pushed towards potentially more lucrative studies ("science"). Combined with the proposition that, other things being equal, better paid graduates should be taxed more than low paid ones, this implies some degree of cross-...nancing of arts studies.

If exort were observable, students should be required to take the very type of degree that they would have chosen, in the presence of full contingent markets. Since study exort is not observable, the choice of subject mix should be distorted. In the absence of either perfect contingent markets, or government policy, there would be two kinds of distortion. First, some who could have bene. tted from going to university would not do so. Second, those who would go to university would choose a more scienti..c mix of subjects than is ed cient. The second-best policy pushes in the opposite direction, in the sense that it requires arty students to specialize in their preferred subjects even further than they would have done otherwise. That is because pushing such students into taking more arts subjects makes studying "easier" (less costly, more pleasurable) for them, and it thus reduces the cost to the education authority of providing them with the incentive to study hard. In second best, not all those 
who could have bene..tted from a university education will necessarily do so.

The ..nding that second-best scholarships and graduate taxes should depend on academic performance gives rise to a practical issue that we have not discussed so far. If the education authority could observe only ..nal degree results, our ..nding would imply that at least part (perhaps a large part) of the award should be paid on graduation only. That would be a problem, because we are assuming that students cannot support themselves by borrowing. Fortunately, however, partial results are general ly available at fairly frequent intervals, such as the quarter or the year. T he scholarship can then be paid in instal Iments, and the total amount adjusted quarterly or yearly as the examination record builds up.

If the random components of the university results of dixerent agents are related in the technical sense explained in the text, the second-best scholarship that a person receives as a student, and the second-best tax that he will have to pay as a graduate, take account not only of his own degree result, but also of those of other students. A n implication, if the correlation is positive, is that an (upward) grade drift should not fool the education authority into giving every student a higher scholarship, or charging every graduate a lower tax. By contrast, even if the random components of graduate incomes were positively correlated, the secondbest tax payable by a graduate takes only account of his income, and not also of the incomes of others. The reason for this asymmetry is that income comparisons do not convey information, additional to that already provided by grade comparisons, on the amount of study exort that a person put in as a student. ${ }^{19}$

Having established that the amount of money a person should optimally pay as a graduate does not depend on the amount of public money received as a student, the latter cannot be interpreted as a loan, or the former as a loan re-payment. A ny direct link between individual payments and receipts would in fact impose an unnecessary constraint on the design of policy. Even a loose link, as envisaged in an income contingent loan scheme, does not appear to be justi..ed on theoretical grounds. There is, furthermore, nothing in the analytical results to suggest that the optimal policy could be run as two parallel schemes, one awarding "student grants" on the basis of "need" (lack of parental sup-

\footnotetext{
${ }^{19} \mathrm{~T}$ hat is strictly true, however, only because we are assumed that the probability of a high income depends only on dregree type, and degree result. Income comparisons would be relevant, in determining the level of the tax, if we allowed for the fact that income depends not only on quali..cations, but also on exort in ..nding and keeping a good job.
} 
port), and the other awarding "scholarships" on the basis of "merit" (academic performance):

Our analysis presupposes the existence of a school system which makes it possible for every child to reveal his natural talent, and his aptitude for dixerent types of studies. Therefore, our conclusions do not apply with equal force to an institutional setting where school attendance (or access to good schools) is restricted by ability to pay, or where premature specialization may prevent individual characteristics from being revealed to the full.

\section{Appendix}

In this A ppendix we brieły examine the consequences of the assumption of at liated random variables on the form of the likelihood ratio $\frac{f_{e}}{f}: A$ full discussion of this topic is in Luporini (2002).

Following the standard approach (Mirrlees, 1974), we have treated the..nal degree results, $x^{j}$, as random variables with joint density $f(x ; e)$, parameterized by the vector of agents' exorts, e: In other words, we have implicitly assumed that, given a certain level of exort, the result is affected by a random 3 component. A Iternatively, we could consider $x^{j}$ as a function, $x^{j}=x_{j} \quad e ; \mu^{j}$, of both exort, $e^{j}$, and a random variable, $\mu^{j}$, representing the infuence of luck on university results. Let $x^{j}$ be monotonically increasing in both $e^{i}$ and $\mu$ : Let $\mu=\mu^{j}$. If we assume that the elements of $\mu$ have joint density $g(\mu), f(x ; e)$ becomes the transformation obtained from $g$ via the functions $x_{j}$.

A ssume that the elements of $\mu$ are ac liated, non-independent random variables. For simplicity, we consider a bivariate case where $\mathrm{j}=\mathrm{A}$; $\mathrm{B}$, but de. nitions and results generalize to multivariate random variables. A bivariate random variable $\mu^{A} ; \mu^{B}$ is said to be ac liated (Milgrom and Weber, 1982; Tong, 1980) if

$$
g^{3} \bar{\mu}^{A} ; \bar{\mu}^{B^{\prime}} g^{3} \mu^{A} ; \mu^{B}, g^{3} \bar{\mu}^{A} ; \mu^{B^{\prime}} g^{3} \mu^{A} ; \bar{\mu}^{B^{\prime}} 8 \bar{\mu}^{A}>\mu^{A} \text { and } \bar{\mu}^{B}>\mu^{B} \text { : }
$$

A $₫$ liation broadly means that the random variables tend to move together, i.e. that a high realization of $\mu^{A}$ is more likely in the case of a high than in the case of a low realization of $\mu^{B}$. Note that independent random variables are ac liated since, in that case, (21) al ways holds as an equation.

Consider now (13) for agent A (the same argument obviously holds for agent B). We can write 


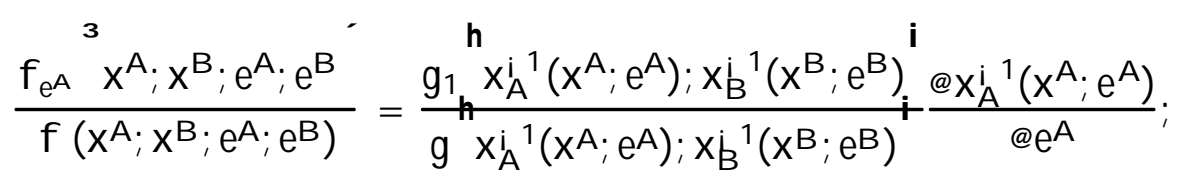

where $\frac{@_{A}^{i}{ }^{1}\left(x^{A} ; e^{A}\right)}{œ^{A}}<0$ : As a consequence, for $\frac{f_{e^{A}} x^{A} ; x^{B} ; e^{A} ; e^{B}}{f\left(x^{A} ; x^{B} ; e^{A} ; e^{B}\right)}$ to be decreasing in $x^{B}, \frac{g_{1} x_{A}^{i}{ }^{1}\left(x^{A} ; e^{A}\right) ; x_{B}^{i}{ }^{1}\left(x^{B} ; e^{B}\right)}{g x_{A}^{i}{ }^{1}\left(x^{A} ; e^{A}\right) ; x_{B}{ }^{1}\left(x^{B} ; e^{B}\right)}+$ must be increasing in $x_{B}^{1}$ :

Note that, for any $\bar{\mu}^{A},>\mu^{A}$,

$$
\frac{g_{3}{ }^{3} \mu^{A} ; \mu^{B}}{g \mu^{A} ; \mu^{B}}=\exp _{3}^{2}{ }_{\mu^{A}} \frac{g_{1}{ }^{3} \mu^{A} ; \mu^{B},}{g \mu^{A} ; \mu^{B}} d \mu^{A} \text { : }
$$

Therefore, (21) implies that $\frac{g_{1} \mu^{A} ; \mu^{B}}{g \mu^{A} ; \mu^{B}}$ is increasing in $\mu^{k}$.

\section{R eferences}

Barbaro, S. (2002), The Distributional Impact of Subsidies to Higher Education: Empirical Evidence from Germany, Gottingen University, mimeo.

Barr, N. (1991), Income-Contingent Student Loans: An Idea Whose Time Has Come, in G.K. Shaw (ed.) Economics, Culture and Education: Essays in Honour of Mark Blaug. London: Edward Elgar

Cigno, A., Luporini, A. and A. Pettini (2003), Transfers to Families with Children as a Principal-A gent Problem, J ournal of Public Economics 87, 1165-1177

Friedman, M. (1962), Capitalism and Freedom, The University of Chicago Press, Chicago.

Hansen, L. and B. Weisbrod (1969), Bene.ts, Costs and Finance of Public Higher E ducation, Markham, Chicago.

Holmström, B. (1982), M oral Hazard in Teams, B ell J ournal of Economics, 13, 324-40.

Holmström, B. and P. Milgrom (1990), Regulating Trade A mong A gents, J ournal of Institutional and Theoretical E conomics, 146, 85-105.

Kim, S.K. (1995), E $₫$ ciency of an Information System in an A gency Model, Econometrica, 63, 89-102.

J orgenson, D.W . and B.M. Fraumeni (1992), Investment in E ducation and U.S. Economic Growth, Scandinavian J ournal of Economics 94, 351-70 
Luporini, A. (2002), Principal Multi-A gent Models under the First Order A pproach: A Characterization, University of Triest, mimeo.

M as-Colell, A., Whinston, M., and J. Green (1995), Microeconomic Theory, Oxford University Press, Oxford.

Milgrom, P.R. and R.J. Weber (1982), A Theory of Auctions and Competitive Bidding, Econometrica, 50, 1089-1122.

M irrlees, J .A . (1974), Notes on Welfare E conomics, Information and Uncertainty, in Balch M.S., McFadden D.L. and S.Y. Wu (eds.) Essays on E conomic Behavi or and Uncertainty, North-H olland, A msterdam.

M ookherjee, D. (1984), O ptimal Incentive Schemes with M any A gents, Review of E conomic Studies, 51, 433-446.

R obbins, E.H. and B. Sarath (1998), Ranking A gencies under Moral Hazard, E conomic Theory, 11, 129-155.

Sinclair-Desgagné, B. (1994), The First-Order A pproach to MultiSignal Principal-Agent Problems, Econometrica, 62, 459-465.

Stiglitz, J. and A. Weiss (1981), Credit Rationing in Markets with Imperfect Information, American Economic Review, 71, 393-410.

Tong, Y.L. (1980), P robability Inequalities in Multivariate Distributions, A cademic Press, N ew Y ork. 


\title{
CESifo Working Paper Series
}

\author{
(for full list see www.cesifo.de)
}

908 Robert A.J. Dur and Otto H. Swank, Producing and Manipulating Information, April 2003

909 Christian Gollier, Collective Risk-Taking Decisions with Heterogeneous Beliefs, April 2003

910 Alexander F Wagner, Mathias Dufour, and Friedrich Schneider, Satisfaction not Guaranteed - Institutions and Satisfaction with Democracy in Western Europe, April 2003

911 Ngo Van Long, Raymond Riezman, and Antoine Soubeyran, Trade, Wage Gaps, and Specific Human Capital Accumulation, April 2003

912 Andrea Goldstein, Privatization in Italy 1993-2002: Goals, Institutions, Outcomes, and Outstanding Issues, April 2003

913 Rajshri Jayaraman and Mandar Oak, The Signaling Role of Municipal Currencies in Local Development, April 2003

914 Volker Grossmann, Managerial Job Assignment and Imperfect Competition in Asymmetric Equilibrium, April 2003

915 Christian Gollier and Richard Zeckhauser, Collective Investment Decision Making with Heterogeneous Time Preferences, April 2003

916 Thomas Moutos and William Scarth, Some Macroeconomic Consequences of Basic Income and Employment Subsidies, April 2003

917 Jan C. van Ours, Has the Dutch Miracle Come to an End?, April 2003

918 Bertil Holmlund, The Rise and Fall of Swedish Unemployment, April 2003

919 Bernd Huber and Marco Runkel, Optimal Design of Intergovernmental Grants under Asymmetric Information, April 2003

920 Klaus Wälde, Endogenous Business Cycles and Growth, April 2003

921 Ramon Castillo and Stergios Skaperdas, All in the Family or Public? Law and Appropriative Costs as Determinants of Ownership Structure, April 2003

922 Peter Fredriksson and Bertil Holmlund, Improving Incentives in Unemployment Insurance: A Review of Recent Research, April 2003 
923 Bernard M.S. van Praag and Adam S. Booij, Risk Aversion and the Subjective Time Discount Rate: A Joint Approach, April 2003

924 Yin-Wong Cheung, Kon S. Lai, and Michael Bergman, Dissecting the PPP Puzzle: The Unconventional Roles of Nominal Exchange Rate and Price Adjustment, April 2003

925 Ugo Trivellato and Anna Giraldo, Assessing the 'Choosiness' of Job Seekers. An Exploratory Approach and Evidence for Italy, April 2003

926 Rudi Dornbusch and Stanley Fischer, International Financial Crises, April 2003

927 David-Jan Jansen and Jakob de Haan, Statements of ECB Officials and their Effect on the Level and Volatility of the Euro-Dollar Exchange Rate, April 2003

928 Mario Jametti and Thomas von Ungern-Sternberg, Assessing the Efficiency of an Insurance Provider - A Measurement Error Approach, April 2003

929 Paolo M. Panteghini and Guttorm Schjelderup, Competing for Foreign Direct Investments: A Real Options Approach, April 2003

930 Ansgar Belke, Rainer Fehn, and Neil Foster, Does Venture Capital Investment Spur Employment Growth?, April 2003

931 Assar Lindbeck, Sten Nyberg, and Jörgen W. Weibull, Social Norms and Welfare State Dynamics, April 2003

932 Myrna Wooders and Ben Zissimos, Hotelling Tax Competition, April 2003

933 Torben M. Andersen, From Excess to Shortage - Recent Developments in the Danish Labour Market, April 2003

934 Paolo M. Panteghini and Carlo Scarpa, Irreversible Investments and Regulatory Risk, April 2003

935 Henrik Jacobsen Kleven and Claus Thustrup Kreiner, The Marginal Cost of Public Funds in OECD Countries. Hours of Work Versus Labor Force Participation, April 2003

936 Klaus Adam, George W. Evans, and Seppo Honkapohja, Are Stationary Hyperinflation Paths Learnable?, April 2003

937 Ulrich Hange, Education Policy and Mobility: Some Basic Results, May 2003

938 Sören Blomquist and Vidar Christiansen, Is there a Case for Public Provision of Private Goods if Preferences are Heterogeneous? An Example with Day Care, May 2003

939 Hendrik Jürges, Kerstin Schneider, and Felix Büchel, The Effect of Central Exit Examinations on Student Achievement: Quasi-experimental Evidence from TIMSS Germany, May 2003 
940 Samuel Bentolila and Juan F. Jimeno, Spanish Unemployment: The End of the Wild Ride?, May 2003

941 Thorsten Bayindir-Upmann and Anke Gerber, The Kalai-Smorodinsky Solution in Labor-Market Negotiations, May 2003

942 Ronnie Schöb, Workfare and Trade Unions: Labor Market Repercussions of Welfare Reform, May 2003

943 Marko Köthenbürger, Tax Competition in a Fiscal Union with Decentralized Leadership, May 2003

944 Albert Banal-Estañol, Inés Macho-Stadler, and Jo Seldeslachts, Mergers, Investment Decisions and Internal Organisation, May 2003

945 Kaniska Dam and David Pérez-Castrillo, The Principal-Agent Matching Market, May 2003

946 Ronnie Schöb, The Double Dividend Hypothesis of Environmental Taxes: A Survey, May 2003

947 Erkki Koskela and Mikko Puhakka, Stabilizing Competitive Cycles with Distortionary Taxation, May 2003

948 Steffen Huck and Kai A. Konrad, Strategic Trade Policy and Merger Profitability, May 2003

949 Frederick van der Ploeg, Beyond the Dogma of the Fixed Book Price Agreement, May 2003

950 Thomas Eichner and Rüdiger Pethig, A Microfoundation of Predator-Prey Dynamics, May 2003

951 Burkhard Heer and Bernd Süssmuth, Cold Progression and its Effects on Income Distribution, May 2003

952 Yu-Fu Chen and Michael Funke, Labour Demand in Germany: An Assessment of NonWage Labour Costs, May 2003

953 Hans Gersbach and Hans Haller, Competitive Markets, Collective Decisions and Group Formation, May 2003

954 Armin Falk, Urs Fischbacher, and Simon Gächter, Living in Two Neighborhoods Social Interactions in the LAB, May 2003

955 Margarita Katsimi, Training, Job Security and Incentive Wages, May 2003

956 Clemens Fuest, Bernd Huber, and Jack Mintz, Capital Mobility and Tax Competition: A Survey, May 2003 
957 Edward Castronova, The Price of 'Man' and 'Woman': A Hedonic Pricing Model of Avatar Attributes in a Synthetic World, June 2003

958 Laura Bottazzi and Marco Da Rin, Financing Entrepreneurial Firms in Europe: Facts, Issues, and Research Agenda, June 2003

959 Bruno S. Frey and Matthias Benz, Being Independent is a Great Thing: Subjective Evaluations of Self-Employment and Hierarchy, June 2003

960 Aaron Tornell and Frank Westermann, Credit Market Imperfections in Middle Income Countries, June 2003

961 Hans-Werner Sinn and Wolfgang Ochel, Social Union, Convergence and Migration, June 2003

962 Michael P. Devereux, Measuring Taxes on Income from Capital, June 2003

963 Jakob de Haan, Jan-Egbert Sturm and Bjørn Volkerink, How to Measure the Tax Burden on Labour at the Macro-Level?, June 2003

964 Harry Grubert, The Tax Burden on Cross-Border Investment: Company Strategies and Country Responses, June 2003

965 Kirk A. Collins and James B. Davies, Measuring Effective Tax Rates on Human Capital: Methodology and an Application to Canada, June 2003

966 W. Steven Clark, Using Micro-Data to Assess Average Tax Rates, June 2003

967 Christopher Heady, The 'Taxing Wages' Approach to Measuring the Tax Burden on Labour, June 2003

968 Michael P. Devereux and Alexander Klemm, Measuring Taxes on Income from Capital: Evidence from the UK, June 2003

969 Bernhard Eckwert and Itzhak Zilcha, The Effect of Better Information on Income Inequality, June 2003

970 Hartmut Egger and Josef Falkinger, The Role of Public Infrastructure for Firm Location and International Outsourcing, June 2003

971 Dag Morten Dalen and Trond E. Olsen, Regulatory Competition and Multi-national Banking, June 2003

972 Matthias Wrede, Tax Deductibility of Commuting Expenses and Residential Land Use with more than one Center, June 2003

973 Alessandro Cigno and Annalisa Luporini, Scholarships or Student Loans? Subsidizing Higher Education in the Presence of Moral Hazard, June 2003 